\title{
The continuum of theory and practice
}

\author{
Henk ten Have ${ }^{1}$
}

Published online: 11 September 2017

(C) Springer International Publishing AG 2017

Public health ethics is a new area of bioethics. It has emerged a few decades ago as a subspecialty. Ethical issues in public health are not new. Examples are vaccination and quarantine that have instigated debates about public interests that might justify restrictions of individual freedom of movement. These concerns have now intensified due to emerging infectious diseases and biosecurity threats. In several countries there are acrimonious debates on childhood vaccination. This context has necessitated public health programs to pay attention to ethics and make sure that future professionals in this field are better equipped to deal with social and ethical concerns. As Victoria Doudenkova et al. (2017) show in this issue, ethics education is introduced in Schools of Public Health. They conclude that in the United States where public health ethics education is most developed, the majority of programs do not offer courses that are required. The number of ethics courses has not much increased since the beginning. The quality is also very different, although a model curriculum has been developed. In Europe the situation seems somewhat better. Most Schools of Public Health have included some ethics content in programs. This is possibly due to the long- standing attention to social medicine in most European countries. This has nothing to do with socialism. When I was a medical student at Leiden University in the Netherlands the medical curriculum included a substantial program in social medicine, focusing on issues as substance abuse and addiction, health insurance, occupational health, and poverty. Students also have to do internships in neighborhood centers and local clinics. Public health institutions exist all over Europe but they were particularly well developed and active in communist countries. After the collapse of the Soviet Union they were initially neglected and sometimes privatized but later in the 1990s it became clear that many so-called 'transition' countries faced serious public health challenges. The role of public health institutions in these countries therefore was resurrected. Andrija Štampar School of Public Health in Zagreb, Croatia, was founded in 1926. The school was completely renovated; it placed itself in the center of many national and

Henk ten Have

tenhaveh@duq.edu

1 McAnulty College and Graduate School of Liberal Arts, Center for Healthcare Ethics, Duquesne University, Fisher Hall 300, 600 Forbes Avenue, Pittsburgh, PA 15282, USA 
international activities. It also introduced ethics education as one of its pillars, especially emphasizing human rights (Ten Have et al. 2005). Doudenkova and colleagues point out that ethics education in public health should be expanded. It provides a good connection between theory and practice so that it may help professionals to address the problems they encounter in their practices. What is helpful is that they also discuss the barriers to this type of education.

Here they mention variability concerning goals and methods; there also is a gap between public health practitioners who are often focused on empirical data and technical skills, and ethicists who are focused on theory and reflection. Furthermore, public health issues are closely related to politics and economics. Emerging infections are frequently related to unhygienic practices of intensive animal farming. The individual victims of infections need treatment and care but the roots of the problem are in the economic system that only drives on productivity, profits and efficiency. The ethical discourse therefore should not merely focus on personal autonomy but on wider social and economic issues of justice, vulnerability and solidarity. Doudenkova and colleagues finally argue that more research will be necessary. This will first require sharing of experiences and making international comparisons. This journal can be the platform for such research.

This issue presents other contributions that show the connections between theory and practice in ethics education. Avci (2017) reports on his continuous research project on quality of ethics teaching, and pays special attention to the role of goals in education. Other contributions discuss specific methods of instruction and the role of virtue ethics. A different dimension is demonstrated in examining experiences with specific target groups, in particular midwives and members of clinical ethics committees.

\section{References}

Avci, Ercan. 2017. A normative analysis to determine the goals of ethics education through three approaches: Rational moral education, ethical acculturation, and learning througout life. International Journal of Ethics Education 2(2): in this issue.

Doudenkova, Victoria, Jean-Christophe Bélisle-Pipon, Louise Ringuette, Vardit, Ravitsky, and Bryn WilliamsJones. 2017. Ethics education in public health: Where are we now and where are we going? International Journal of Ethics Education 2(2): in this issue.

Ten Have, Henk, Ana Borovecki, and Stepan Oreskovic. 2005. Master programme Health, human rights and ethics: A curriculum development experience at Andrija Stampar School of Public Health, medical school, University of Zagreb. Medicine, Health Care and Philosophy 8: 371-376. 